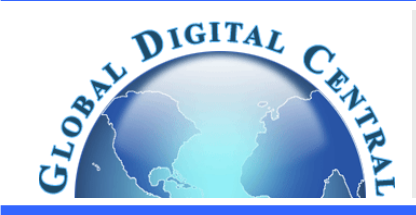

Frontiers in Heat and Mass Transfer

\title{
HEAT TRANSFER AND FLOW PROFILES IN ROUND TUBE HEAT EXCHANGER EQUIPPED WITH VARIOUS V-RINGS
}

\author{
Amnart Boonloi ${ }^{\mathrm{a}}$ and Withada Jedsadaratanachai ${ }^{\mathrm{b}, *}$ \\ ${ }^{a}$ Department of Mechanical Engineering Technology, College of Industrial Technology, King Mongkut's University of Technology North Bangkok, \\ Bangkok 10800, Thailand \\ ${ }^{b}$ Department of Mechanical Engineering, School of Engineering, King Mongkut's Institute of Technology Ladkrabang, Bangkok 10520, Thailand
}

\begin{abstract}
This study numerically investigates pressure loss, heat transfer and thermal efficiency in round tube heat exchangers attached with various types of Vrings. A typical type A V-ring is compared with two types of modified V-rings (type B and C). The impacts of blockage ratios, b/D $=0.05,0.10,0.15$ and 0.20 for all V-ring types in the turbulent region are discussed $(\mathrm{Re}=3000-20,000)$. Flow directions in the round pipe attached with the $\mathrm{V}$-rings are varied. The V-apex setting downstream is referred to as "V-Downstream, while the V-apex setting upstream is referred to as "V-Upstream". The flow and heat transfer profiles in the tested section are analyzed using the finite volume method (a commercial code with the SIMPLE algorithm). The thermal performance of the tested tube is measured in terms of dimensionless variables: thermal enhancement factor (TEF), Nusselt number (Nu) and friction factor (f). Numerical results reveal that type B and C V-rings can reduce pressure drop compared with type A V-ring. Additionally, the VUpstream of type $\mathrm{C}$ V-ring yields the maximum $\mathrm{TEF}$ of 3.10 at $\mathrm{b} / \mathrm{D}=0.05$.
\end{abstract}

Keywords: V-ring; turbulator; Nusselt number; pressure drop; thermal efficiency.

\section{INTRODUCTION}

Increasing energy demand has driven the need to improve the efficiency of heat exchanger systems in industrial plants. There are many ways to improve thermal performance. Adding external power such as vibration to the heating/cooling systems to increase heat transfer is one example. This heat transfer augmentation with additional power is called "active method". This method has a tendency to increase operation cost. Another way to increase the ability to transfer heat is called "passive method". It attaches vortex generators such as ribs (Eiamsa-ard et al. (2019)), baffles (Phila et al. (2020)), twisted tapes (Piriyarungrod et al. (2018)), etc. to create vortex flows/swirling flows. The passive method has been adopted extensively because it does not increase operation cost. Hence, this study also selects the passive method as a mean to increase thermal performance.

Much work has been done to examine the use of passive methods to enhance thermal performance of various types of heat exchanges. For examples, Bahiraei et al. (2020) examined the heat transfer enhancement in a square section attached with $\mathrm{V}$-shaped ribs and nanofluid. The $45^{\circ}$ $\mathrm{V}$-shaped rib was compared with the $60^{\circ} \mathrm{V}$-shaped rib. They found that the $45^{\circ} \mathrm{V}$-shaped rib resulted in lower entropy than that of the $60^{\circ} \mathrm{V}$ shaped rib and concluded that the bigger rib height with smaller pitch spacing performed lower exergy destruction and increased the second law efficiency. Bahiraei et al. (2019) numerically studied the thermohydraulic performance of $\mathrm{Cu}$-water nanofluid in a square duct placed with $90^{\circ} \mathrm{V}$-shaped ribs. The effect of rib configurations: rib heights and rib pitches were compared. They showed that the Nusselt number increased by $28.3 \%$ when the rib height was increased from 2.5 to 7.5 $\mathrm{mm}$ with the pitch distance of $50 \mathrm{~mm}$. Matsubara et al. (2020) performed direct simulation of entry regime heat transfer in a channel attached with ribs at $\operatorname{Re}=20,460$. They found that the disturbed thermal boundary enhanced heat transfer at the entry regime of the ribbed channel. Li et al.
(2020) studied heat transfer and flow characteristics in a microchannel with solid and porous ribs. The thermal performance in the microchannel attached with the ribs was found to be greater than the mirochannels with no ribs. Bahiraei et al. (2020) examined nanofluid in a channel equipped with conical ribs using the second law analysis. The influence of rib arrangements and nanoparticle shapes on flow and heat transfer patterns were measured. Jiang et al. (2020) investigated the fluid flow and heat transfer mechanisms of two-phase flow in a rectangular section with column-row-ribs. Bai et al. (2019) studied the effect of ribs on heat transfer at the entrance of a pin-fin array $(\mathrm{Re}=7000-40,000)$. Three configurations of ribs: $60^{\circ}$ rib, V-shaped rib and $\mathrm{W}$-shaped rib, were assessed. They found that the entrance effect not only enhanced the heat transfer rate, but also decreased the pressure drop. Li et al. (2019) evaluated pressure loss and heat transfer of turbulent flow in a channel with miniature structured ribs on one wall. Their results showed that the averaged Nusselt number and the overall Nusselt number are $2.2-2.6$ and 2.9 - 3.3 times, respectively, greater than those of the smooth channel. Bai et al. (2019) numerically studied pressure loss and heat transfer of a pin-fin array attached with rib turbulators. They reported that the rib produces the secondary flow which accounts for heat transfer enhancement. They also found that the $90^{\circ}$ rib performs the best. Jedsadaratanachai et al. (2015) simulated the thermo-hydraulic performance in a circular pipe fitted with $45^{\circ} \mathrm{V}$-baffles. The V-baffles in the form of inline arrangement were attached in the pipe. The effects of blockage ratios and flow directions in the Re range of $100-2000$ (laminar regime) were examined. It was found that the disturbed thermal boundary layer enhanced heat transfer and thermal efficiency in the pipe. The maximum thermal enhancement factor was 3.2. Jedsadaratanachai and Boonloi (2014) selected $30^{\circ}$ double V-baffles to augment heat transfer coefficient in a square channel. The effects of blockage ratios and pitch spacing in the laminar region with Re between 100 and 1200 were examined. They found that the increased blockage ratio with the declined pitch spacing led to the augmentation of the heat transfer rate. 
Boonloi and Jedsadaratanachai (2016) studied the forced convective heat transfer and pressure loss of a square channel with discrete combined baffles. The impact of flow path and baffled height for the thermal performance were examined in the Re range of $5000-20,000$. They reported that the heat transfer in the channel with the discrete combined baffle was $2.8-6$ times better than that of the smooth channel. Boonloi and Jedsadaratanachai (2015) reported that the $30^{\circ}$ and $45^{\circ}$ wavy ribs in a square channel had the best thermal performance of 1.47 and 1.52 , respectively, at $\mathrm{Re}=3000$.

This research focuses on the V-ring in the round pipe heat exchanger as the V-shaped turbulators have been found to increase heat transfer performance (Jedsadaratanachai and Boonloi (2017), Boonloi and Jedsadaratanachai (2019a, b), Boonloi and Jedsadaratanachai (2018a, b), Boonloi and Jedsadaratanachai (2014)). The V-ring and discrete V-ring are attached in the round pipe heat exchanger to change the flow structure. The V-ring and discrete V-ring will generate vortex flows which in turn disturb the thermal boundary layer on the tube wall. The disruption of the thermal boundary layer can significantly increase heat transfer and thermal efficiency. The configurations, sizes and placement of the V-ring and discrete V-ring in the round pipe heat exchanger are analyzed. The numerical investigation is chosen to study fluid flow and heat transfer patterns. Insights about the mechanisms in the heat exchanger is the key to thermal performance improvement in heat exchangers.

\section{PHYSICAL DOMAIN OF THE ROUND PIPE ATTACHED WITH VARIOUS V-RINGS}

The round pipe heat exchangers attached with three V-ring types are depicted in Fig. 1, while the periodic modules are shown in Fig. 2. The general configuration of the V-ring with an additional bar at the middle is called "type A". The additional bar can help to improve the rigidity of the turbulator when inserted in the tested section. The bar will also enhance the flow mixing. The discrete V-rings are known as "type B" and "type C". The purposes for the creation of type B and C discrete Vrings are to facilitate the turbulent blending of the fluid flow and reduce pressure loss. The reduction of pressure loss and the increment of turbulent mixing may enhance thermal efficiency. The tube diameter for all models is fixed at $0.05 \mathrm{~m}$. The V-ring height is represented with " $\mathrm{b}$ ". The ratio of the V-ring height to the round pipe diameter, $b / D$, is varied in the range of $0.05-0.20$. The middle bar at the central line of the tested section is fixed at $0.05 \mathrm{D}$ in all configurations. The middle bar should not be larger than $5 \%$ of the tube diameter because it may bring high pressure loss. The flow attack angle of the V-ring is set at $30^{\circ}$ for all domains. According to past research, this angle provides optimum values of both heat transfer and pressure drop in the tested section (Jedsadaratanachai and Boonloi (2014), Boonloi and Jedsadaratanachai (2015)). The periodic length of the round pipe attached with various V-ring types is "L" and set to be equal to the round pipe diameter, $\mathrm{L}=\mathrm{D}$. The length between the V-rings, $\mathrm{P}$, is set to be equal to the tube diameter $(\mathrm{P} / \mathrm{D}=1)$. The flow directions in the tested tube are V-Downstream and VUpstream. The flow setting with $\mathrm{V}$-apex directing downstream is called "V-downstream", while the reverse setting is called "V-Upstream". The turbulent flow region with the Re number between 3000 and 20,000 is selected in this study.

\section{ASSUMPTIONS, INITIAL CONDITION AND BOUNDARY CONDITIONS}

Numerical analysis of three-dimensional, steady state fluid flow and heat transfer in the round tube heat exchanger attached with V-rings is performed under the following assumptions.
Forced convective heat transfer in the tested section is considered, while radiation heat transfer and natural convection are ignored.

The tested fluid is air and its thermal properties are assumed to be constant at the average bulk mean temperature (300K).

Body force and viscous dissipation are negligible.

Both inlet and outlet boundaries are assigned with a periodic condition.

Constant heat flux along the tube wall is set at $600 \mathrm{~W} / \mathrm{m}^{2}$, while the V-ring is set as an insulator.

A no-slip boundary condition is applied for all surfaces.

\section{MATHEMATICAL FOUNDATION AND NUMERICAL METHOD}

Based on the assumptions, the governing equations are presented below. Energy equation:

$\frac{\partial}{\partial x_{i}}\left(\rho u_{i} T\right)=\frac{\partial}{\partial x_{j}}\left[\left(\Gamma+\Gamma_{t}\right) \frac{\partial T}{\partial x_{j}}\right]$

Continuity equation:

$\frac{\partial}{\partial x_{i}}\left(\rho u_{i}\right)=0$

Momentum equation:

$\frac{\partial}{\partial x_{i}}\left(\rho u_{i} u_{j}\right)=-\frac{\partial p}{\partial x_{i}}+\frac{\partial}{\partial x_{j}}\left[\mu\left(\frac{\partial u_{i}}{\partial x_{j}}\right)-\rho \overline{u_{i}^{\prime} u_{j}^{\prime}}\right]$

Fluid density, pressure, the mean component of velocity in the direction $x_{i}$, dynamic viscosity and the fluctuating component of velocity are represented with $\rho, p, u_{i}, \mu$ and $u^{\prime}$, respectively.

Molecular thermal diffusivity and turbulent thermal diffusivity are represented with $\Gamma$ and $\Gamma_{\mathrm{t}}$, respectively. $\Gamma$ and $\Gamma_{\mathrm{t}}$ can be calculated using Eq. (4).

$\Gamma=\mu / \operatorname{Pr}$ and $\Gamma_{t}=\mu_{t} / P r_{\mathrm{t}}$

The Reynolds-averaged approach to turbulent modeling requires that the Reynolds stresses, $-\rho \overline{u_{i}^{\prime} u_{j}^{\prime}}$ in Eq. (3), be modeled. Eq. (5) illustrates the Boussinesq hypothesis which relates the Reynolds stresses to the mean velocity gradients.

$-\rho \overline{u_{i}^{\prime} u_{j}^{\prime}}=\mu_{t}\left(\frac{\partial u_{i}}{\partial x_{j}}+\frac{\partial u_{j}}{\partial x_{i}}\right)-\frac{2}{3}\left(\rho k+\mu_{t} \frac{\partial u_{i}}{\partial x_{i}}\right) \delta_{i j}$

$K$ is turbulent kinetic energy, which can be determined by $k=\left(\overline{u_{i}^{\prime} u_{i}^{\prime}}\right) / 2 . \quad \delta_{i j}$ is a Kronecker delta. An advantage of the Boussinesq hypothesis approach is the relatively low computational cost associated with the computation of the turbulent viscosity ( $\mu_{t}=\rho C_{\mu} k^{2} / \varepsilon$ ). The RNG $k-\varepsilon$ turbulent model is an example of the two-equation models that use the Boussinesq hypothesis. The RNG $k-\varepsilon$ model is derived from the instantaneous Navier-Stokes equation using the "renormalization group" (RNG) method. The steady state transport equations are presented in Eqs. (6) and (7)

$$
\begin{aligned}
& \frac{\partial}{\partial x_{i}}\left(\rho k u_{i}\right)=\frac{\partial}{\partial x_{j}}\left(\alpha_{k} \mu_{e f f} \frac{\partial k}{\partial x_{j}}\right)+G_{k}-\rho \varepsilon \\
& \frac{\partial}{\partial x_{i}}\left(\rho \varepsilon u_{i}\right)=\frac{\partial}{\partial x_{j}}\left(\alpha_{k} \mu_{e f f} \frac{\partial \varepsilon}{\partial x_{j}}\right)+C_{1 \varepsilon} \frac{\varepsilon}{k} G_{k}-C_{2 \varepsilon} \rho \frac{\varepsilon^{2}}{k}-\mathrm{R}_{\varepsilon}
\end{aligned}
$$




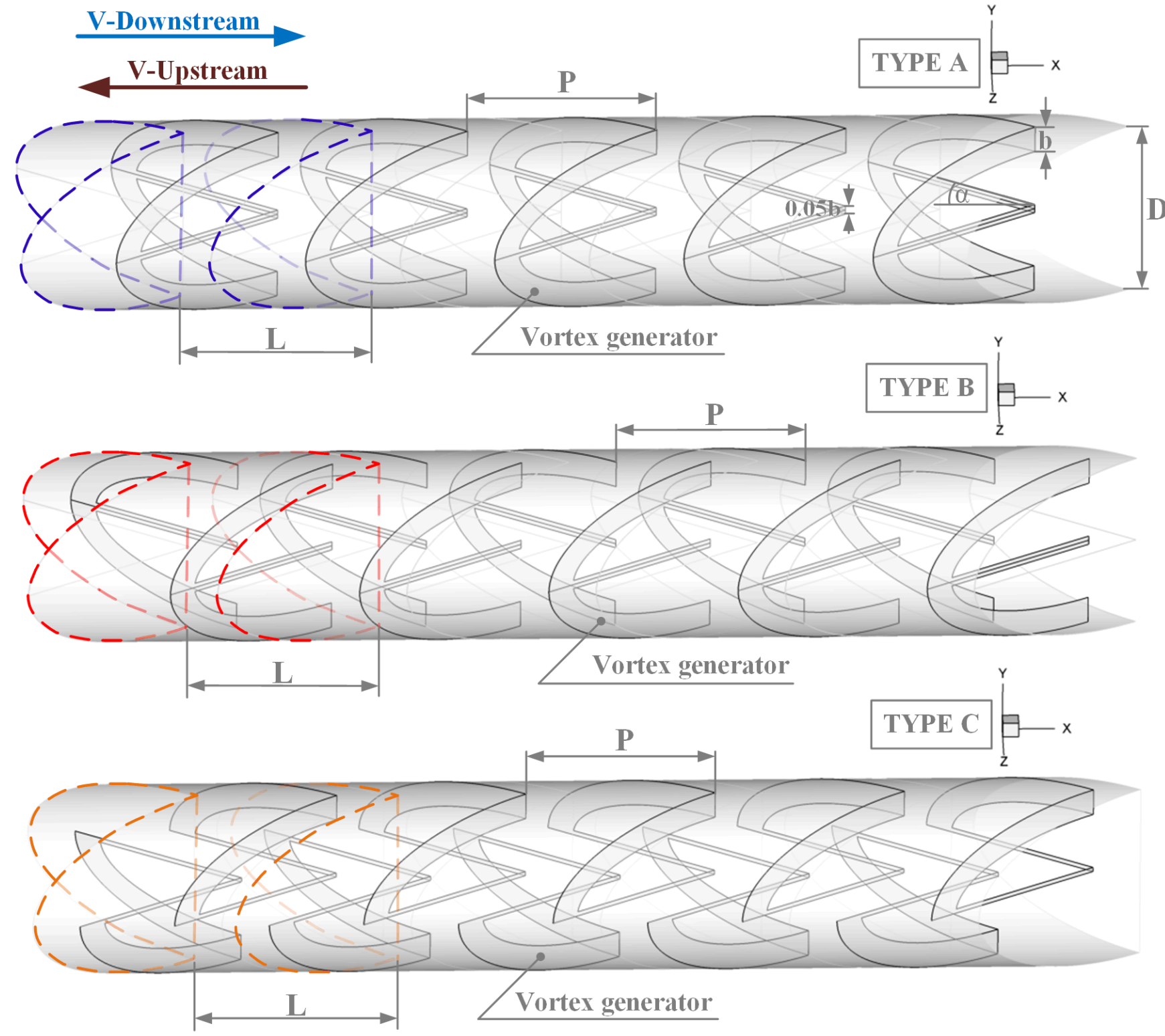

Fig. 1 The round pipe heat exchanger attached with various V-rings.
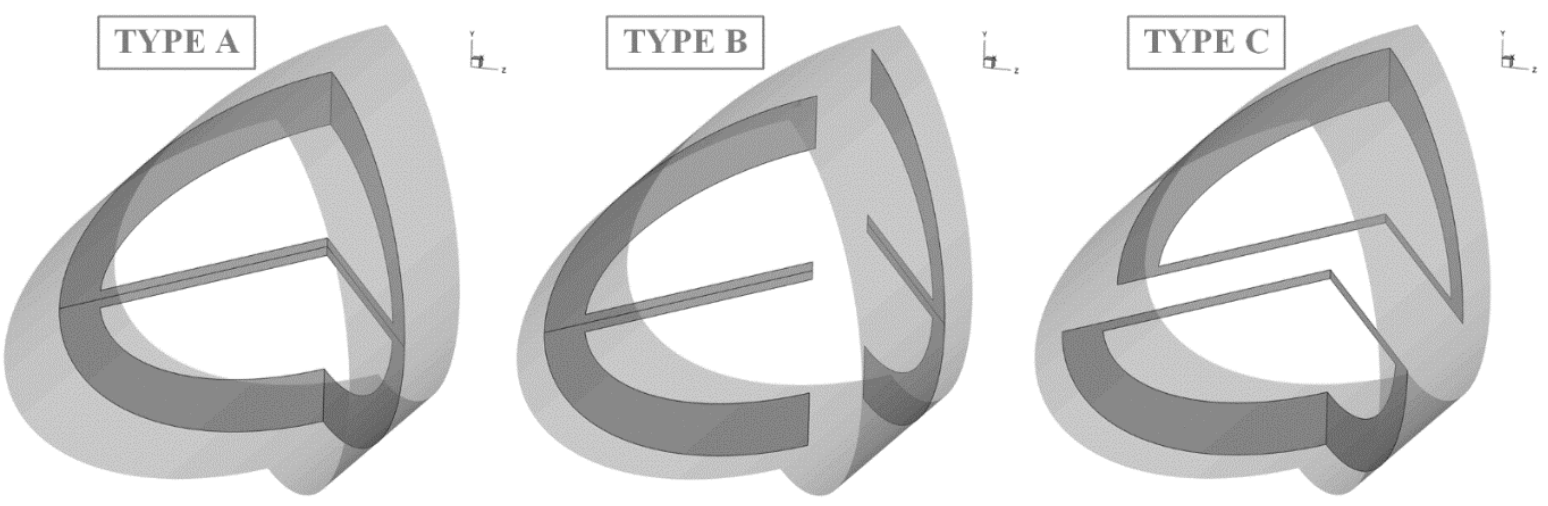

Fig. 2 The configurations of V-rings. 


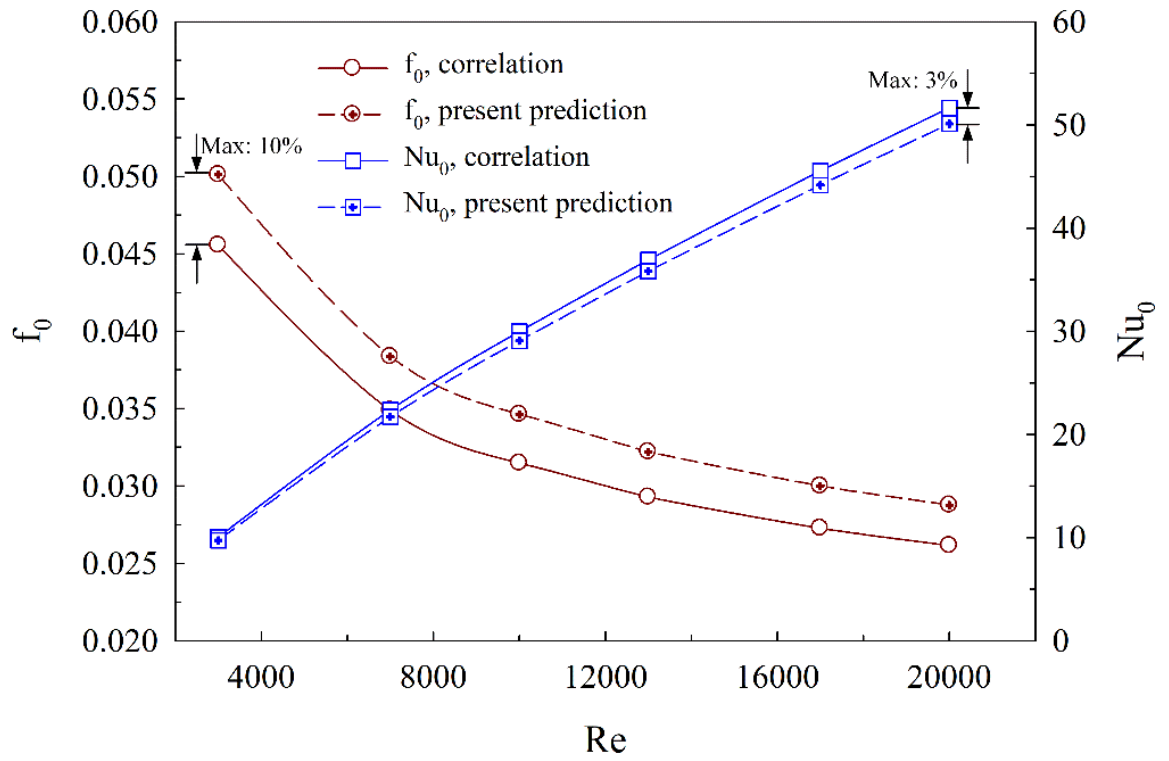

Fig. 3 Validations of Nusselt number and friction factor values in the case of the smooth pipe.

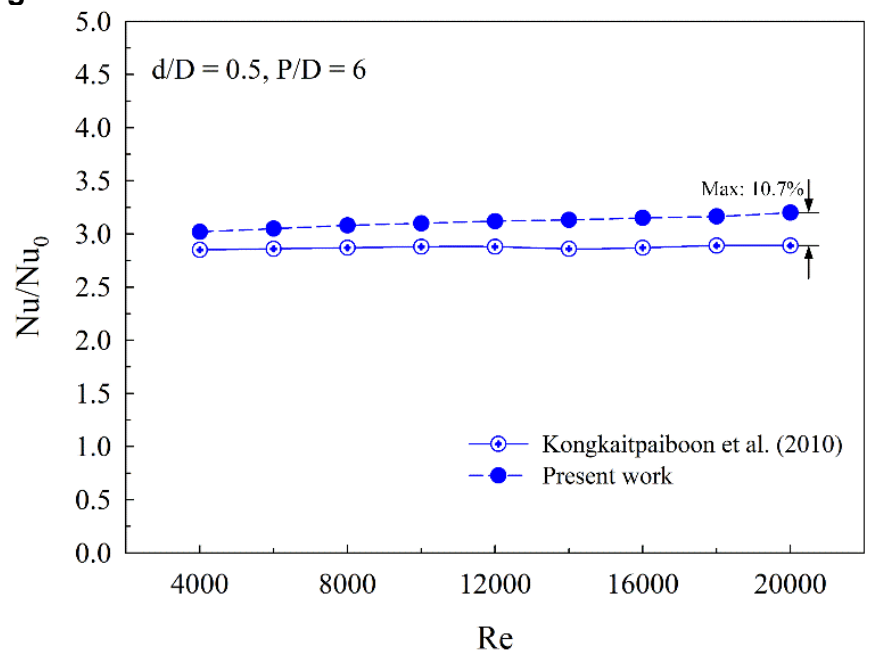

(a)

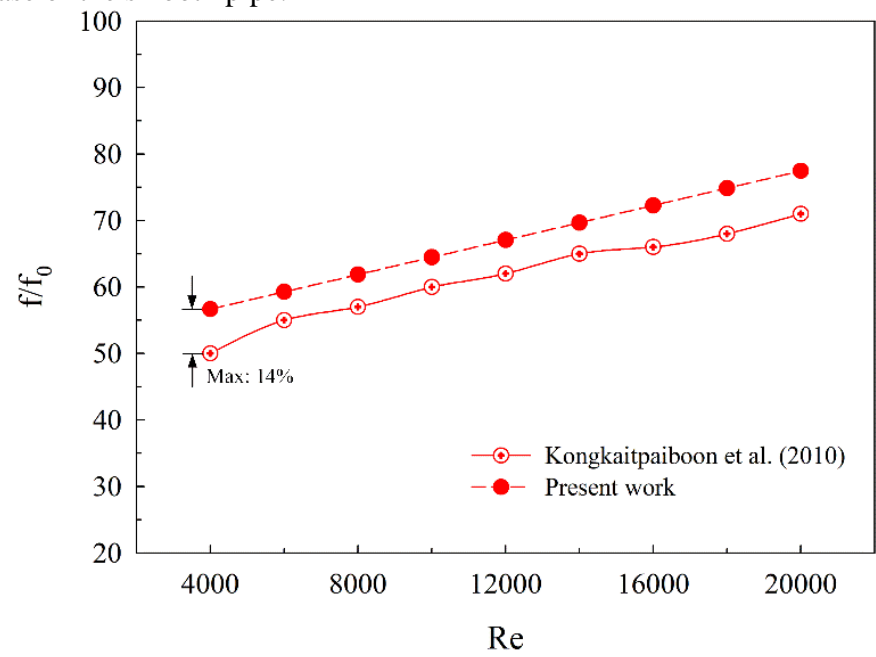

(b)

Fig. 4 Validations of (a) $\mathrm{Nu} / \mathrm{Nu}_{0}$ and (b) f/fo with the experimental results.

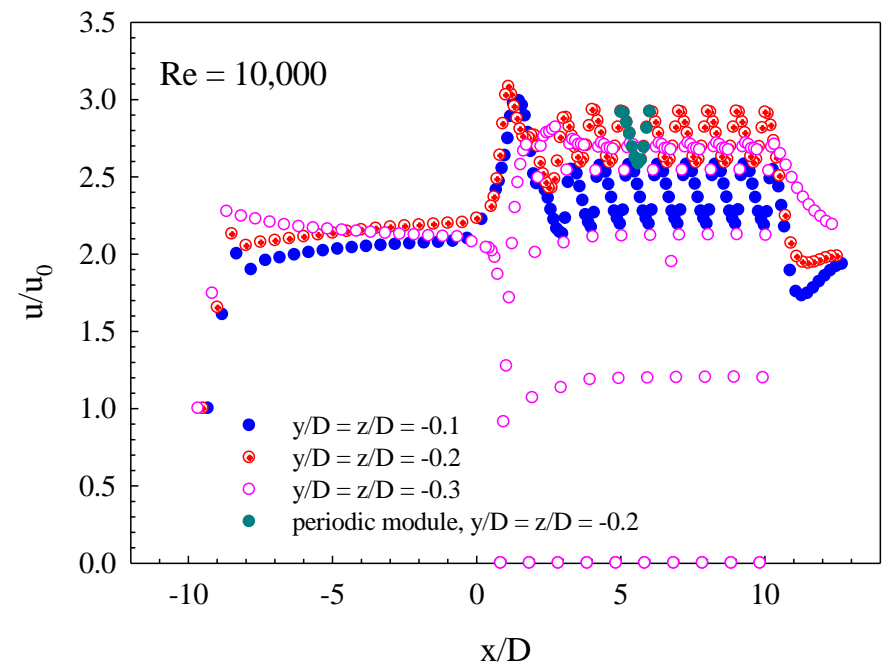

(a)

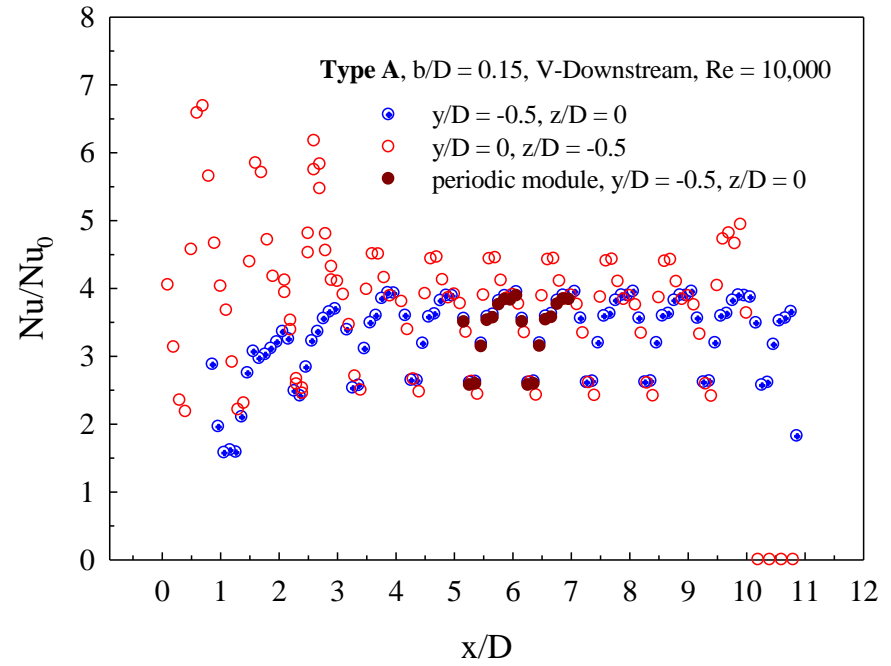

(b)

Fig. 5 Periodic conditions in the round pipe heat exchanger attached with $V$-rings for (a) $u_{1} / u_{0}$ and (b) $\mathrm{Nu} / \mathrm{Nu}_{0}$. 

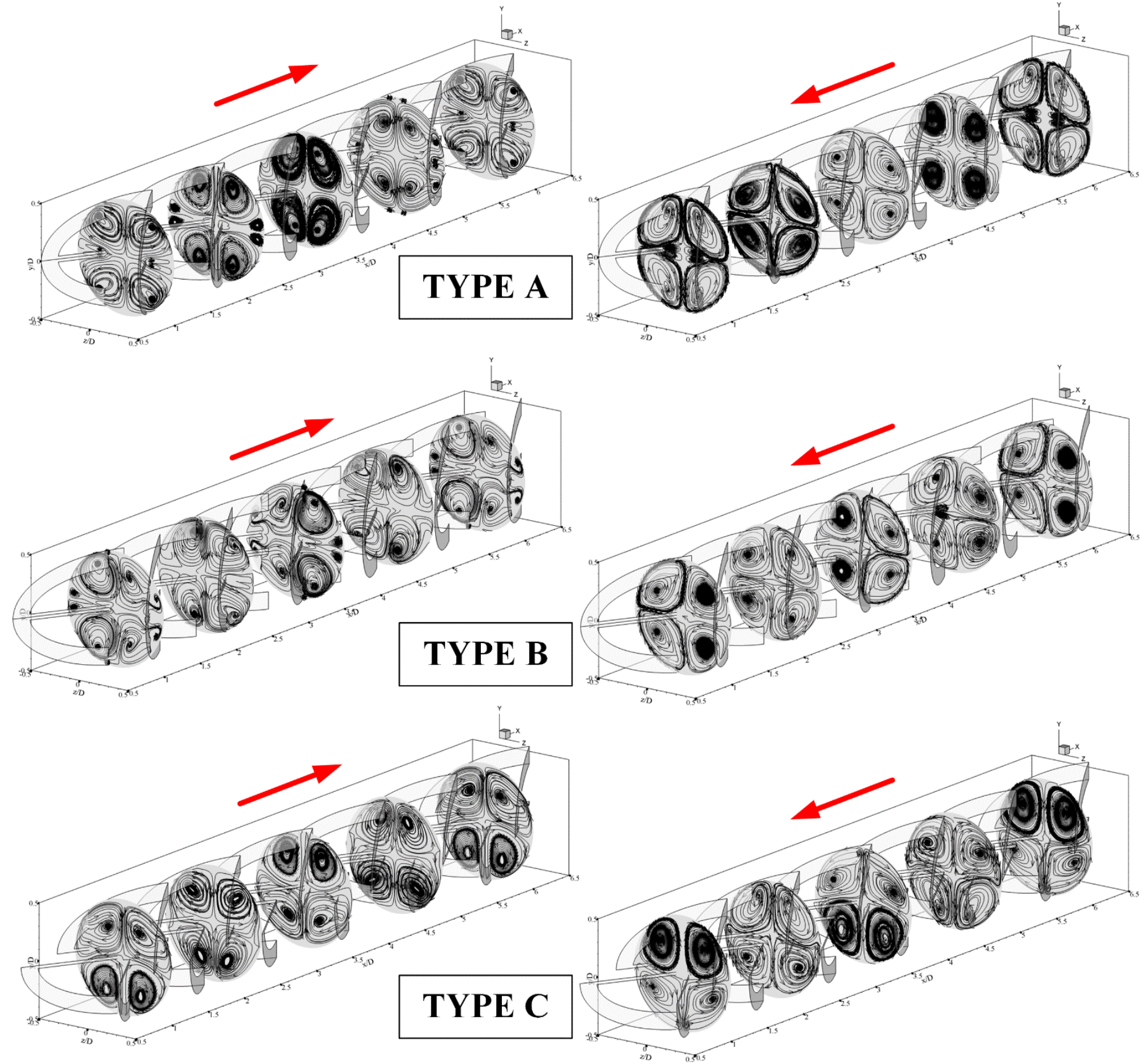

Fig. 6 Streamlines in transverse planes for the round pipe attached with $\mathrm{V}$-rings at $\mathrm{b} / \mathrm{D}=0.15$ and $\mathrm{Re}=10,000$.

The inverse effective Prandtl number for $k$ and $\varepsilon$ are represented with $\alpha_{k}$ and $\alpha_{\varepsilon}$, respectively. $C_{1 \varepsilon}$ and $C_{2 \varepsilon}$ are set as constant values. The effective viscosity, $\mu_{\text {eff }}$, is shown in Eq. (8).

$\mu_{\text {eff }}=\mu+\mu_{t}=\mu+\rho C_{\mu} \frac{k^{2}}{\varepsilon}$

where $C_{\mu}$ is 0.0845 .

The governing equations were discretized by the QUICK scheme together with SIMPLE pressure-velocity decoupling algorithm. The numerical problem of the round pipe attached with V-rings is solved with the finite volume method. When the normalized residual values were less than $10^{-5}$ for all variables, and less than $10^{-9}$ for the energy equation, the solutions were known as convergent.

The important dimensionless variables: Reynolds number, friction factor, local Nusselt number, average Nusselt number and thermal performance enhancement factor are shown in Eqs. (10), (11), (12), (13) and (14), respectively:

$$
\begin{aligned}
& R e=\frac{\rho \bar{u} D}{\mu} \\
& f=\frac{(\Delta p / L) D}{1 / 2 \rho \bar{u}^{2}} \\
& N u_{x}=\frac{h_{x} D}{k} \\
& N u=\frac{1}{A} \int N u_{x} d A \\
& T E F=\left.\frac{h}{h_{0}}\right|_{p p}=\left.\frac{N u}{N u_{0}}\right|_{p p}=\left(N u / N u_{0}\right) /\left(f / f_{0}\right)^{1 / 3}
\end{aligned}
$$


TYPE A

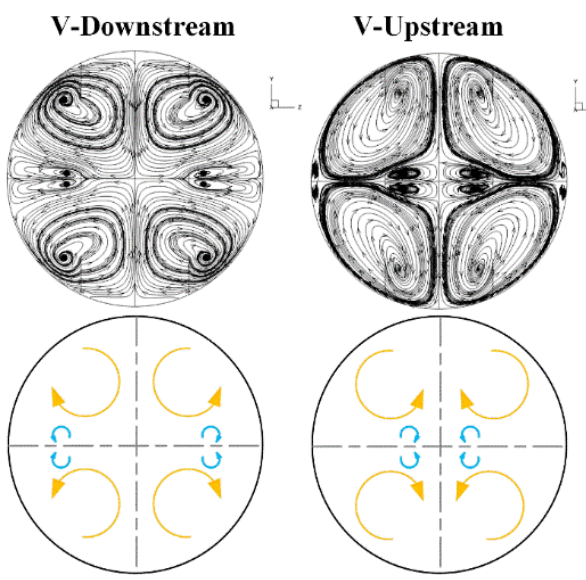

(a)
TYPE B

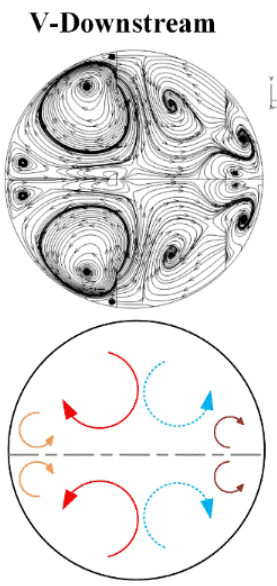

(b)

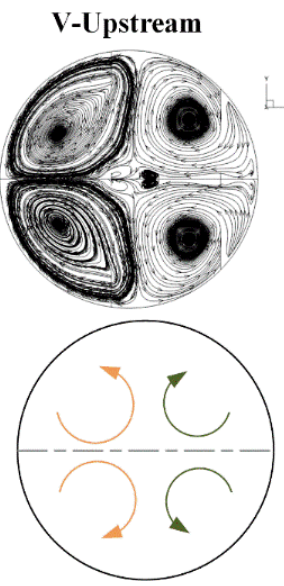

TYPE C

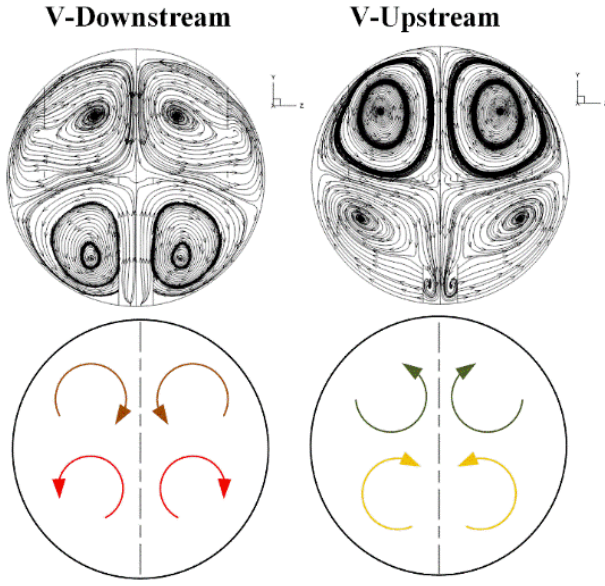

(c)

Fig. 7 Flow patterns in the round pipe heat exchanger attached with various types of V-rings: (a) type A, (b) type B and (c) type C.

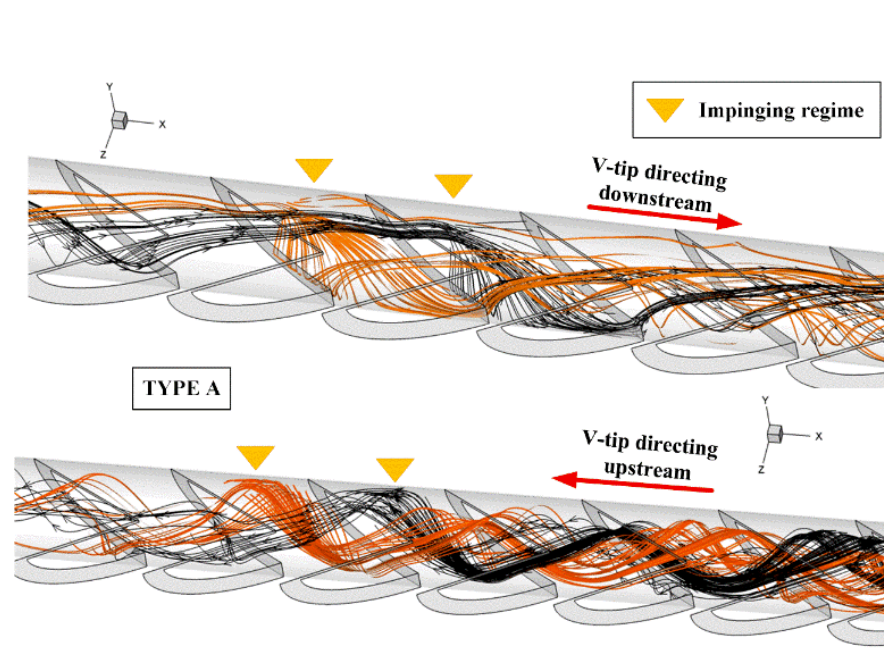

(a)
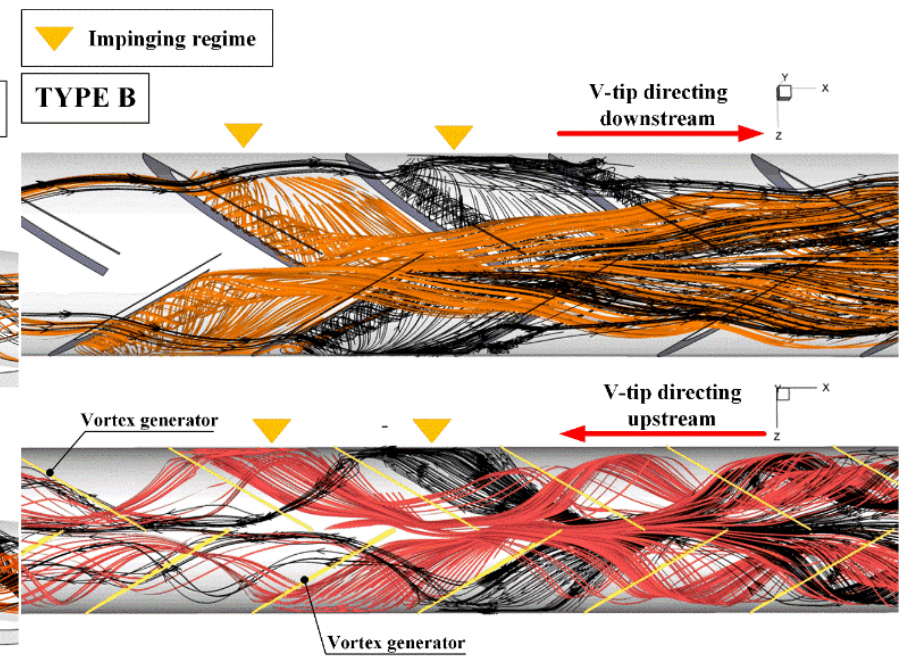

(b)

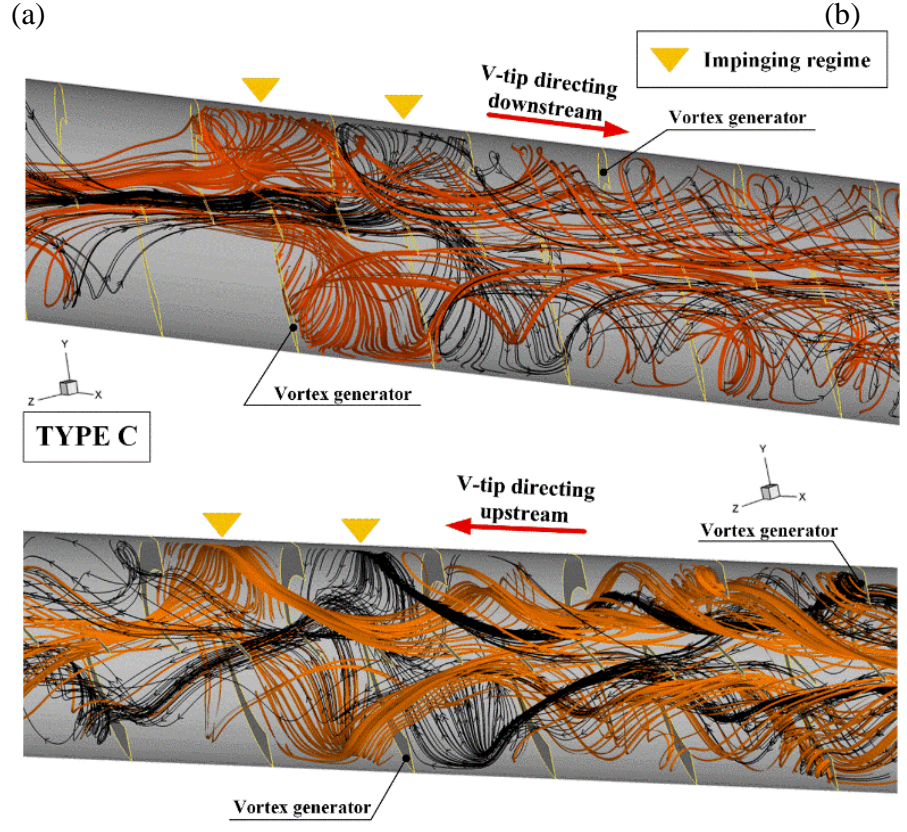

(c)

Fig. 8 Longitudinal flows in the round pipe attached with various types of V-rings: (a) type A, (b) type B and (c) type $\mathrm{C}$ at $\mathrm{b} / \mathrm{D}=0.15$ and $\mathrm{Re}=$ 10,000 . 

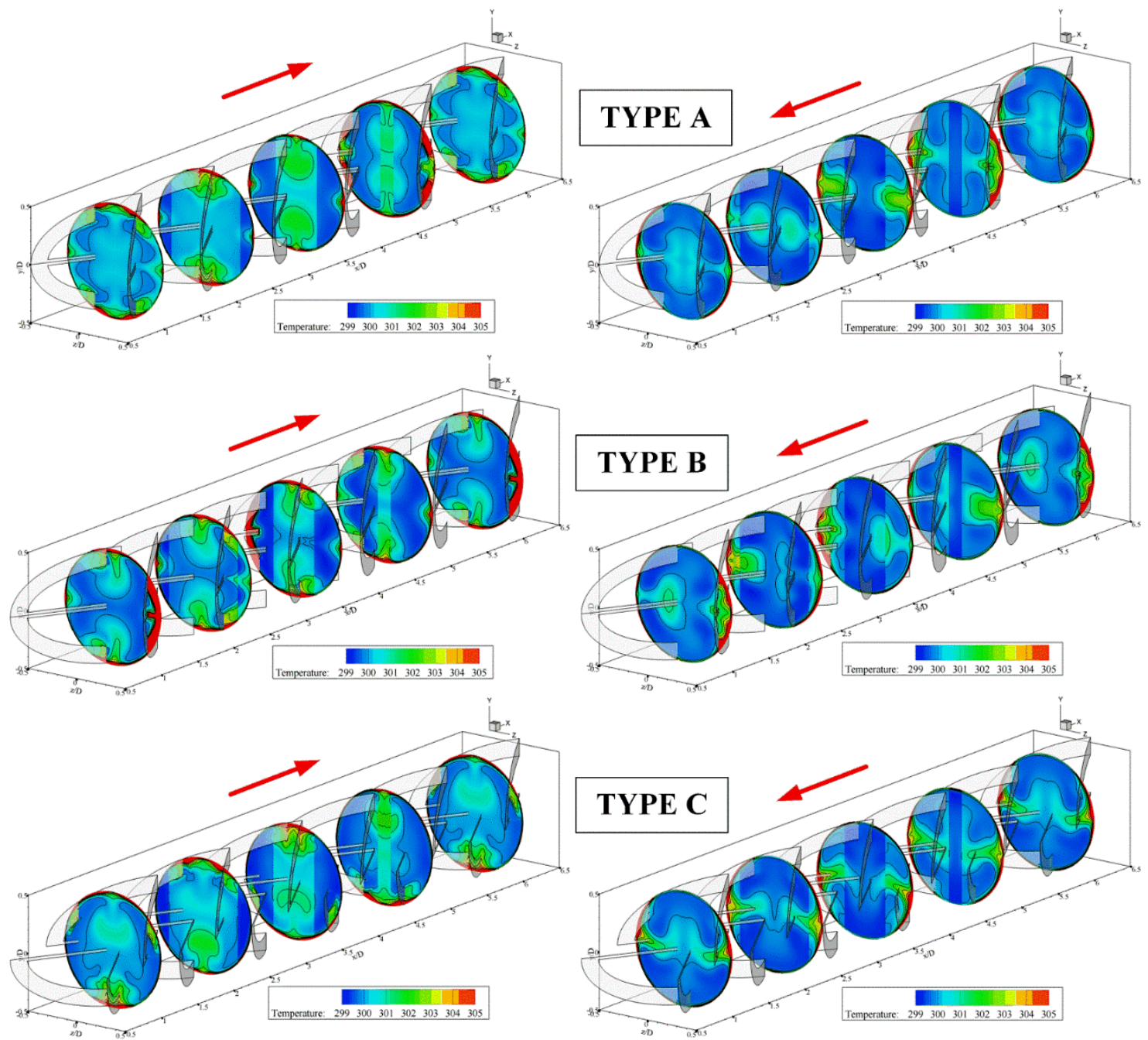

Fig. 9 Temperature distributions in transverse planes for the round pipe attached with V-rings at $b / \mathrm{D}=0.15$ and $\mathrm{Re}=10,000$.

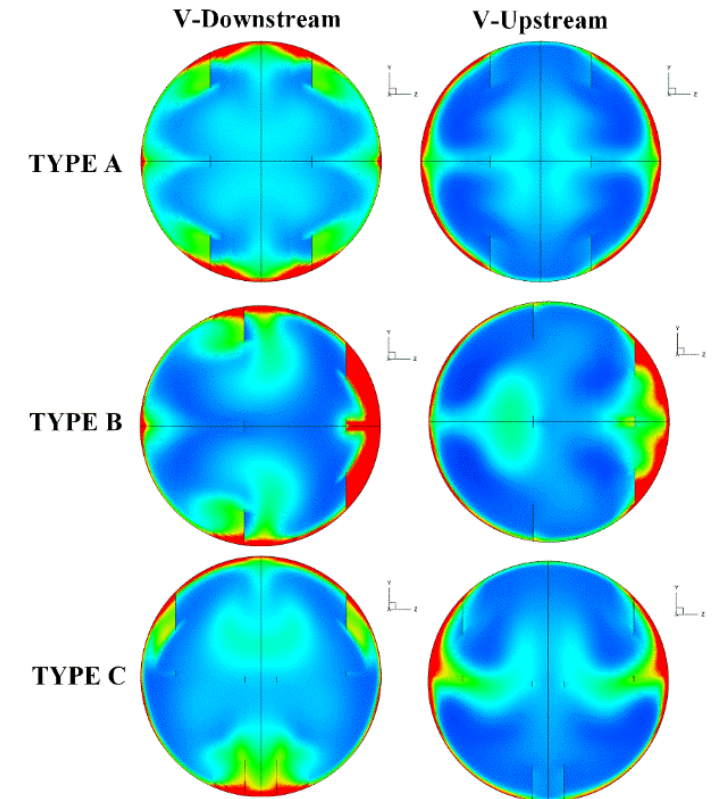

Fig. 10 Heat transfer behavior in the round pipe heat exchanger attached with various types of V-rings in the case of VDownstream and V-Upstream.
The Nusselt number and friction factor for the plain pipe tube are represented with $\mathrm{Nu}_{0}$ and $\mathrm{f}_{0}$, respectively.

\section{NUMERICAL VALIDATIONS}

The numerical validations or the model validation are important for the numerical investigation. The validation results ensure accuracy of the numerical results. The numerical validation of the present work can be divided into 4 parts: smooth pipe validation, grid independence, compared with the experimental results and periodic condition test.

Fig. 3 shows the plots of the smooth pipe validations on heat transfer and friction loss. The Nusselt number and friction factor of the present investigation are compared with the correlations (Cengel and Ghajar (2015)). The Nusselt number and friction factor correlations of the smooth tube are presented in Eqs. (15) and (16), respectively. The difference between the correlations and the results from this study, namely, the Nusselt number and the friction factor values, was less than $10 \%$ and $3 \%$, respectively.

$$
\begin{aligned}
& N u=0.023 \operatorname{Re}^{0.8} \operatorname{Pr}^{0.4} \\
& f=(0.79 \ln \mathrm{Re}-1.64)^{-2}
\end{aligned}
$$

Five models with different numbers of grid cells, 120000, 180000, 220000,280000 and 320000, of the round pipe heat exchangers attached with the V-rings ( $\mathrm{b} / \mathrm{D}=0.15$, V-Downstream, Type $\mathrm{A}, \mathrm{Re}=10,000)$ are compared. It is found that the Nusselt number and friction factor with the grid cells in the range of $180000-320000$ follow a similar trend. The variation of the Nusselt number and friction factor values are within $\pm 8 \%$. 
Therefore, for the sake of computational time and result accuracy, the grid cell number of 180000 is chosen for all numerical models of the round pipe heat exchangers attached with the V-rings.

In Figs. $4 \mathrm{a}$ and $4 \mathrm{~b}$, the Nusselt number and friction factor from the computational domain of the round pipe heat exchanger attached with the general type of orifice $(\mathrm{d} / \mathrm{D}=0.5, \mathrm{P} / \mathrm{D}=6)$ are compared with the experimental results (Kongkaitpaiboon et al. (2010)). The Nusselt number and friction factor values from our numerical simulation differ from the experimental results by $10.7 \%$ and $14 \%$, respectively.

Because the periodic boundary is applied to the inlet and outlet boundaries, the periodic concepts on flow and heat transfer for the round pipe heat exchanger attached with the V-ring are checked. Figs. 5a and $5 b$ show the plots of the $\mathrm{u} / \mathrm{u}_{0}$ and $\mathrm{Nu}_{\mathrm{x}} / \mathrm{Nu}_{0}$ vs the Reynolds numbers, respectively, for the round pipe heat exchanger attached with the type A $\mathrm{V}$-ring $(\mathrm{b} / \mathrm{D}=0.15, \mathrm{~V}$-Downstream, $\mathrm{Re}=10,000)$. The periodic profiles of velocity and heat transfer can be found at the $4^{\text {th }}$ and $3^{\text {rd }}$ module, respectively. This suggests that the periodic boundary is an appropriate condition for the round pipe attached with V-rings.

Based on the results in this section, it can be summarized that the created model of the round pipe heat exchanger attached with V-rings is a reliable mean to determine friction loss, heat transfer, thermal efficiency and mechanisms in the tested section.

\section{TYPE A}

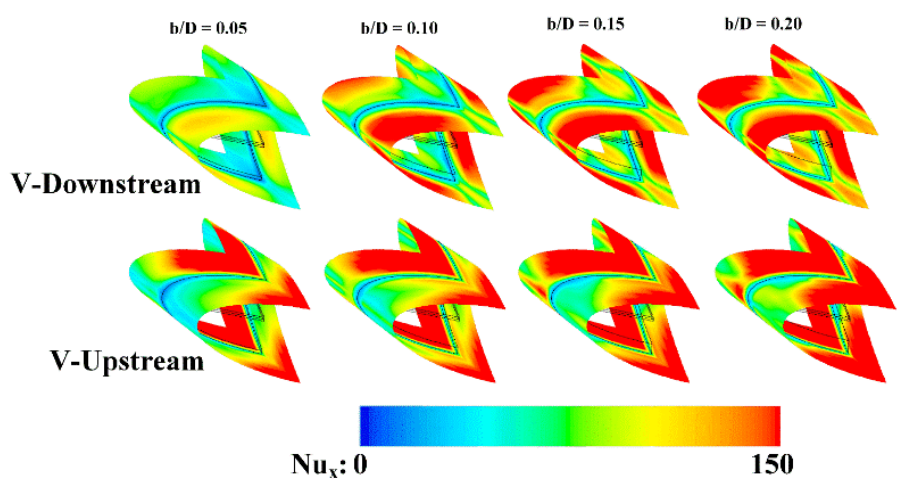

(a)
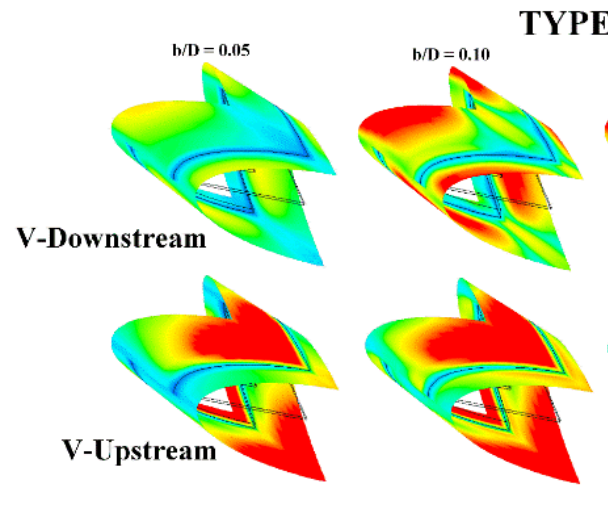

TYPE C
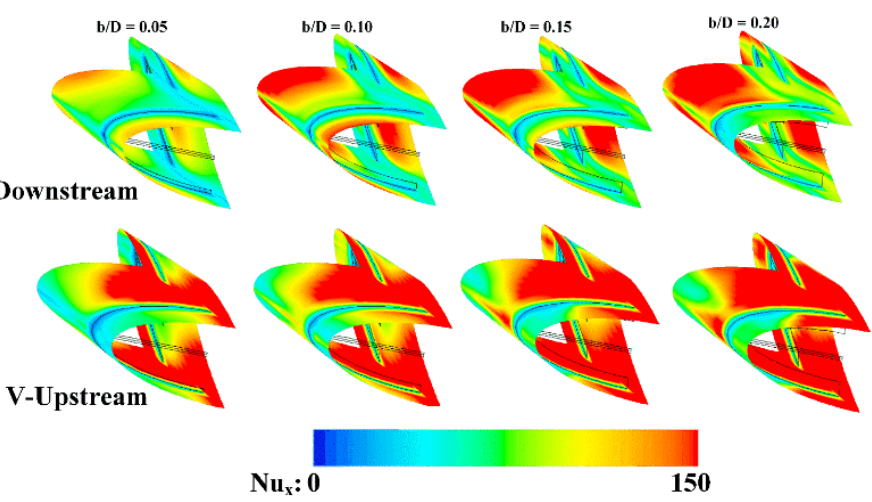

(b)
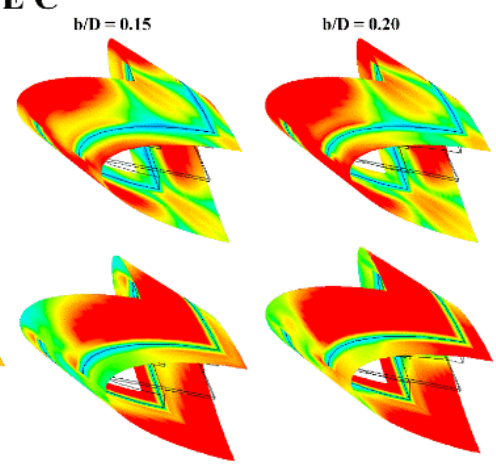

$\mathrm{Nu}_{\mathbf{x}}: \mathbf{0}$

150

(c)

Fig. 11 Local Nusselt number contours for the round pipe attached with various types of V-rings: (a) type A, (b) type B and (c) type C at Re = 10,000.

\section{NUMERICAL RESULTS}

Discussions of numerical results are divided into two sections. First, the mechanisms in the round pipe attached with the V-ring are explained. Insights into the flow and heat transfer profiles in the heat exchanger pipe is crucial for suitable configurations of the V-rings to improve heat transfer. Second, pressure drop, thermal efficiency and the heat transfer rate in the heat exchanger pipe attached with the V-rings are assessed by dimensionless parameters: friction factor, thermal enhancement factor and Nusselt number, respectively.

\subsection{Flow and heat transfer patterns}

In this section, the streamlines in $\mathrm{y}-\mathrm{z}$ axis and longitudinal airstreams are selected to describe the flow configuration in the round pipe heat exchanger attached with the V-rings. The fluid temperature distributions in $y-z$ planes and local Nusselt number distributions on the pipe surface are simulated to show the heat transfer behavior in the tested tube.
Fig. 6 shows the plots of the streamlines in y-z planes for the round pipe heat exchanger attached with various types of $\mathrm{V}$-rings and flow directions. Generally, the three types of V-rings can generate vortex flows along the tested section. Different flow patterns are detected when changing configurations and flow directions.

In the type A model, four major vortex cores can be observed in both flow directions. The symmetric flow at the upper-lower part and left-right part is clearly seen due to the symmetric configuration. Changing flow direction causes the vortex rotation to be in the opposite direction. In the case of the V-Downstream, the small vortices which are created by the additional bar are obviously observed in all transverse planes.

In the type B model, the four main vortex cores are seen for all directions along the tested section. The symmetric flow at the upper and lower regime is found. The flow rotation changes when changing flow directions. The additional bar can also produce small vortices in the tested section. 


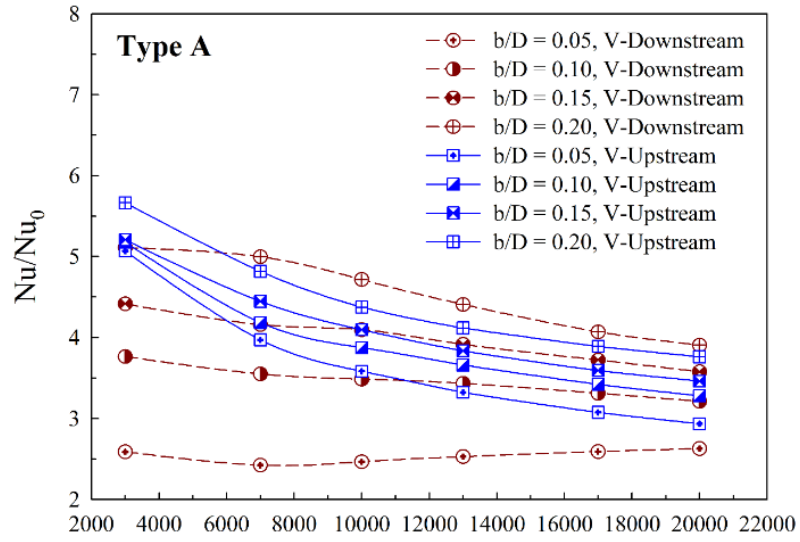

$\operatorname{Re}$

(a)

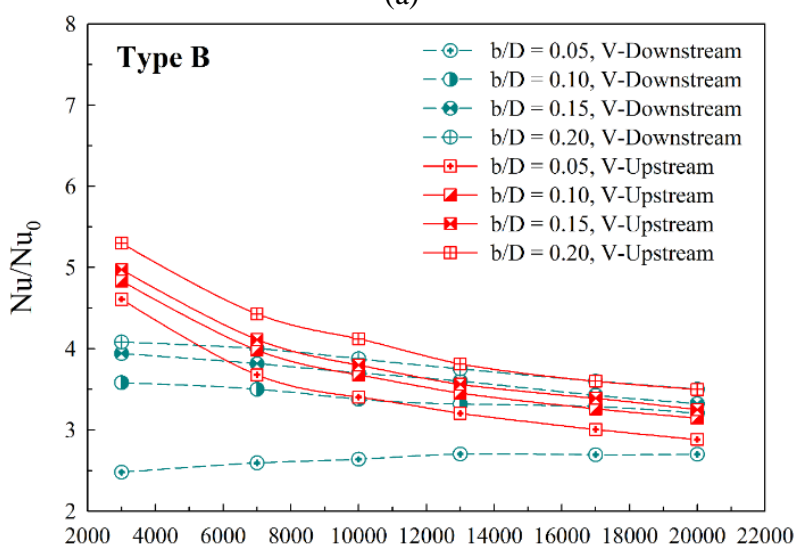

$\operatorname{Re}$

(b)

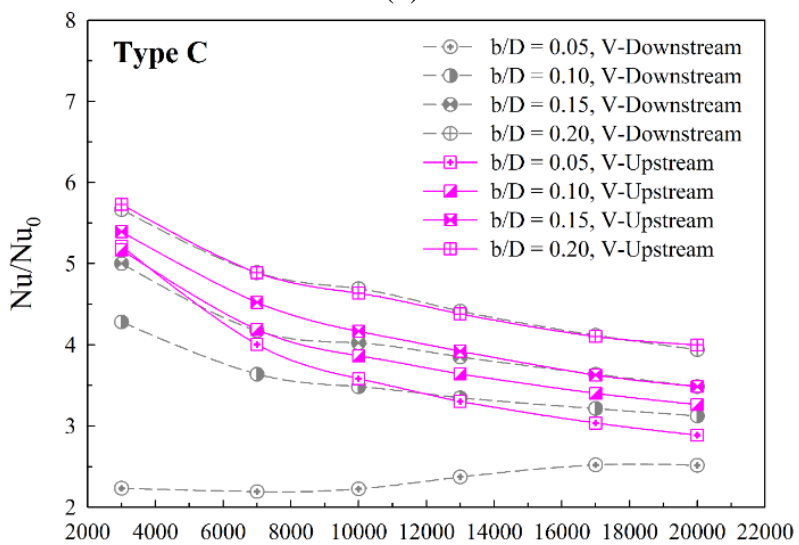

$\operatorname{Re}$

(c)

Fig. $12 \mathrm{Nu} / \mathrm{Nu}_{0}$ vs $\mathrm{Re}$ of the round pipe heat exchanger attached with various types of V-rings: (a) type A, (b) type B and (c) type C.

In the type $\mathrm{C}$ model, the $\mathrm{V}$-rings create four vortex cores along the tested section for both flow directions. The symmetric flow at the left and right section is observed. However, the small vortices, which are produced by the additional bar, cannot be detected. The fluid flow in the pipe heat exchanger attached with the V-rings for the type $\mathrm{A}, \mathrm{B}$ and $\mathrm{C}$ is shown in Figs. 7a, 7b and 7c, respectively.

The longitudinal vortex flows along the round pipe heat exchanger attached with various types of V-rings tested with both fluid flow directions are plotted in Figs. 8a, 8b and 8c. The impinging flows on the tube wall are found for all flow directions and types. The impinging flows are the key to increase heat transfer rate. The impinging flows disturb thermal boundary layer. Heat transfer in the tested section increases due to the disturbance of the thermal boundary layer. It is clear that different turbulator shapes and arrangements result in the impinging flow to occur at different regimes.

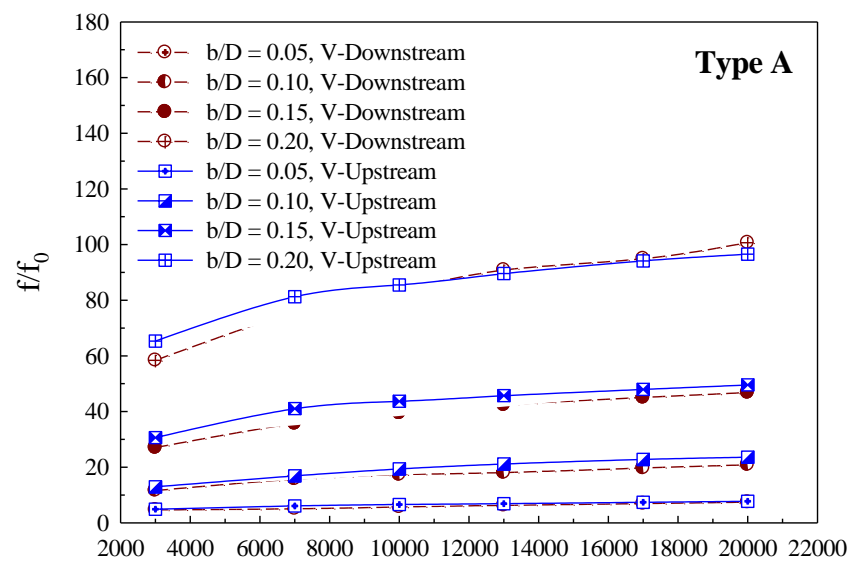

$\operatorname{Re}$

(a)

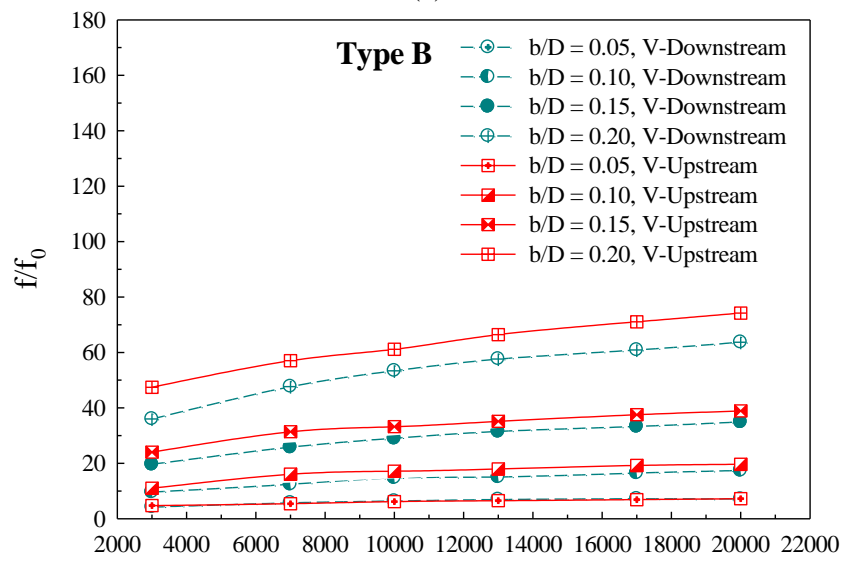

$\operatorname{Re}$

(b)

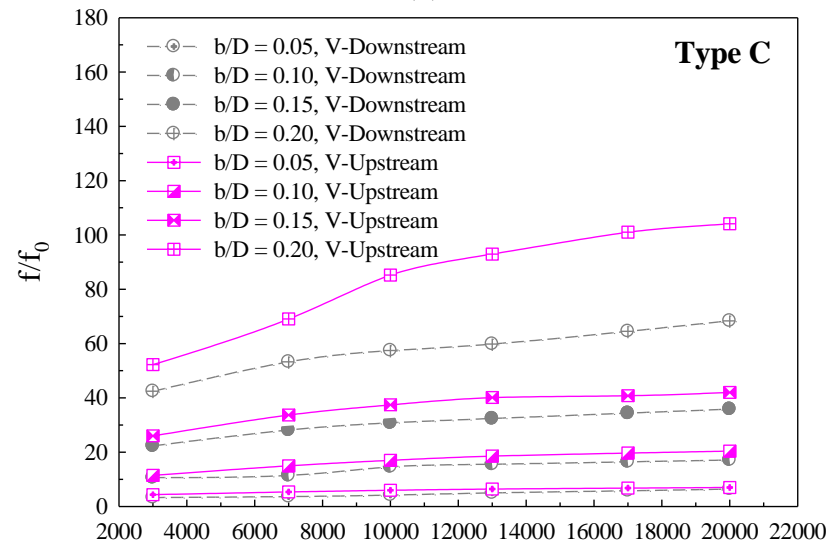

$\operatorname{Re}$

(c)

Fig. $13 \mathrm{f} / \mathrm{f}_{0}$ vs $\mathrm{Re}$ of the round pipe heat exchanger attached with various types of V-rings: (a) type A, (b) type B and (c) type C.

Fig. 9 presents the variation of the temperature contours in transverse planes in the round pipe heat exchanger attached with different V-rings and flow directions. The temperature distributions are an important indicator of the disturbance of the thermal boundary layer near 
the tube wall. The impinging flows near the tube surface reduce the thermal boundary layer thickness.

In the type A model, the reduction of the red contour is found at the left-right zone for the V-Downstream, but for the V-Upstream, it is seen at the upper-lower regime. In the type B model, the disturbance of the thermal boundary layer for both arrangements follow a similar pattern. In the type $\mathrm{C}$ model, the lower red layer is seen at the left-right section for the V-Downstream, but for the V-Upstream, it is seen at the upperlower section. The comparison of the temperature distributions in $\mathrm{y}-\mathrm{z}$ axis for each plane at various cases can be seen in Fig. 10. The variation of heat transfer characteristics in the tested pipe is a result of different flow structure caused by various V-ring types.

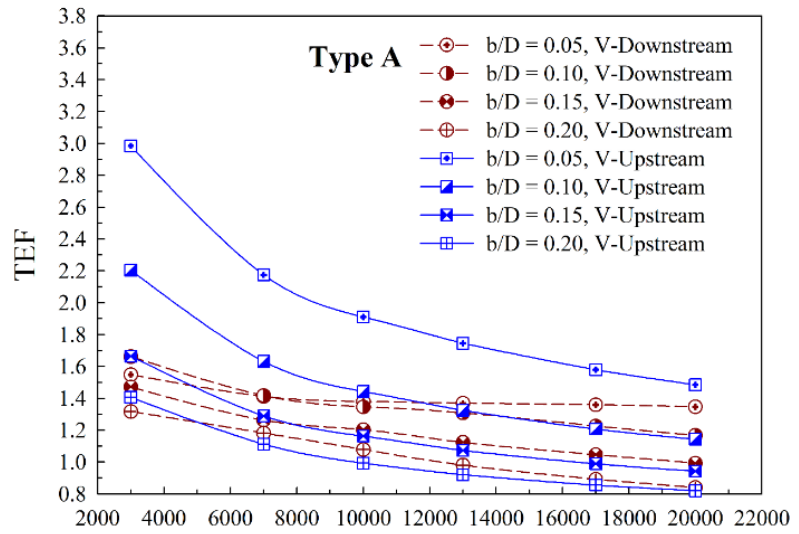

$\mathrm{Re}$

(a)

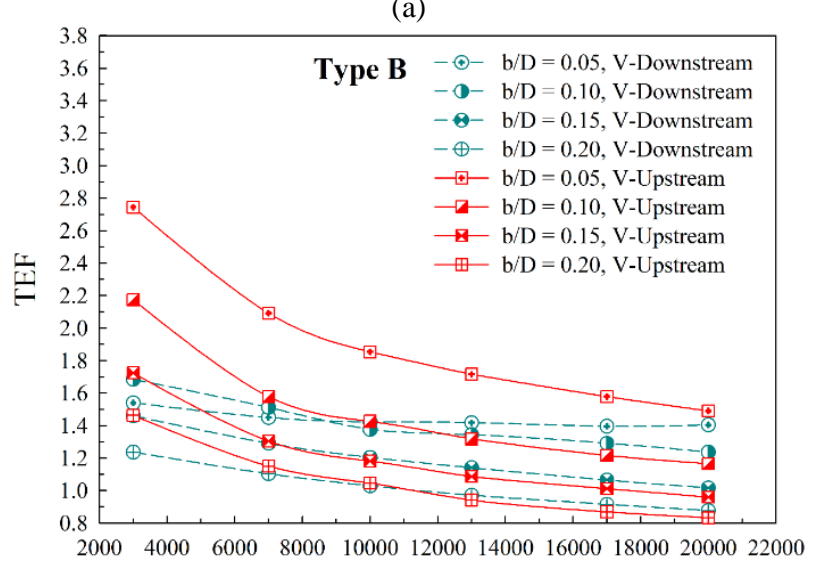

$\mathrm{Re}$

(b)

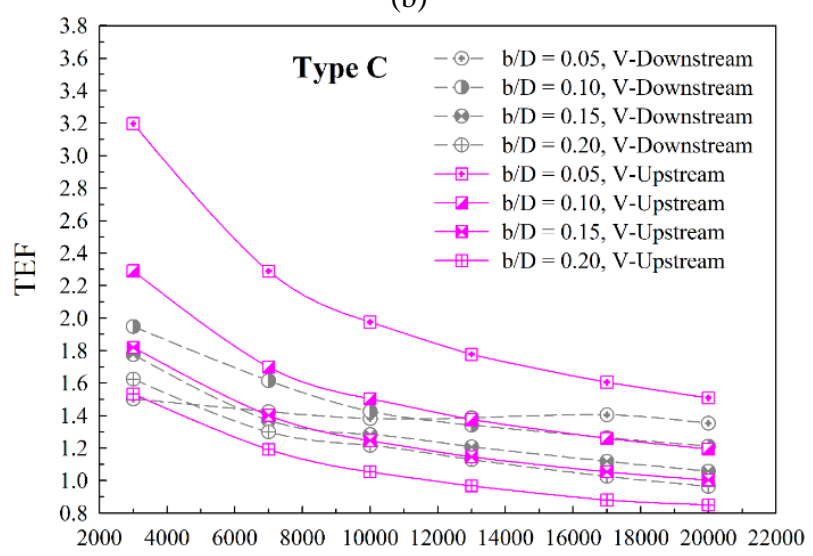

$\operatorname{Re}$

(c)

Fig. 14 TEF vs Re of the round pipe heat exchanger attached with various types of V-rings: (a) type A, (b) type B and (c) type C.
The local Nusselt number distributions on the heat transfer surface are another indicator of the impingements of the vortex flows. Figs. 11a, $11 \mathrm{~b}$ and $11 \mathrm{c}$ illustrate the local Nusselt number distributions on the tube wall of the round pipe heat exchanger attached with the type A, B and C $\mathrm{V}$-rings, respectively. These figures show that heat transfer is higher in the pipe heat exchanger with the V-rings compared with all the other cases with the smooth pipe. The impinging regime on the pipe wall is seen in all types of V-rings and flow arrangements. An increase in the Vring height enhances the vortex strength, which in turn leads to greater heat transfer. For all types of V-rings and flow arrangements, the lowest heat transfer is observed in the condition which $b / D=0.05$, whereas the highest heat transfer is observed in the condition which $\mathrm{b} / \mathrm{D}=0.20$. Regardless of V-ring types, the maximum heat transfer occurs at the leftright section for the V-Downstream, but for the V-Upstream, it occurs at the upper-lower section. This shows that the V-ring can induce the longitudinal flows which impinge at the left-ring part of the tested section for the V-Downstream, but for the V-Upstream, this happens at the upper-lower section. The plots of flow structures and heat transfer characteristics of different configurations of V-rings in the tested section cannot be used to conclude vortex strength and heat transfer. Therefore, the value of Nusselt number is chosen to determine heat transfer. Heat transfer depends on the vortex strength and flow mixing. The friction factor is selected to assess pressure loss in the tested section. Because the attachment of the V-rings in the tube heat exchanger not only enhances heat transfer but also reduces friction loss, the thermal enhancement factor at similar pumping power is presented to discuss the benefit of the V-rings. The friction factor, Nusselt number and thermal enhancement factor values are presented in the next section.

\subsection{Thermal performance analysis}

The thermal performance analysis in the round pipe heat exchanger attached with various types of V-rings is divided into three sections: heat transfer, pressure loss and efficiency. The heat transfer rate of the tested tube can be presented in terms of Nusselt number ratio $\left(\mathrm{Nu} / \mathrm{Nu}_{0}\right)$, while the pressure loss and efficiency can be presented in the form of friction factor ratio $\left(f / f_{0}\right)$ and thermal enhancement factor $(\mathrm{TEF})$, respectively. $\mathrm{The} \mathrm{Nu} / \mathrm{Nu}_{0}$ versus $\mathrm{Re}$ at different $\mathrm{b} / \mathrm{D}$ values for all V-ring types is plotted in Figs. 12a, 12b and 12c. In the case of V-Downstream, the $\mathrm{Nu} / \mathrm{Nu} 0$ in the tested tube is $2.42-5.10,2.48-4.08$ and $2.19-5.67$ for type $\mathrm{A}, \mathrm{B}$, and $\mathrm{C} \mathrm{V}$-rings, respectively. In the case of V-Upstream, the $\mathrm{Nu} / \mathrm{Nu}_{0}$ is $2.93-5.66,2.88-5.30$ and $2.89-5.73$, for type $\mathrm{A}, \mathrm{B}$, and $\mathrm{C}$ V-rings, respectively.

In the case of type $\mathrm{A} \mathrm{V}$-ring, $\mathrm{Nu} / \mathrm{Nu} 0$ decreases with an increase in Reynolds numbers, except when $\mathrm{b} / \mathrm{D}=0.05$ for the $\mathrm{V}$-Downstream. When $0.05 \leq b / D \leq 0.10$, greater heat transfer is observed in the VUpstream compared with the V-Downstream for all Reynolds numbers. At $\mathrm{b} / \mathrm{D}=0.15$, the V-Upstream, compared with the V-Downstream, results in larger Nusselt number when $\mathrm{Re}<10,000$, but lower when $\mathrm{Re}$ $>10,000$. At $\mathrm{b} / \mathrm{D}=0.20$ and $\mathrm{Re}=3000$, the $\mathrm{V}$-Upstream provides greater heat transfer than the V-Downstream.

In the case of type B V-ring, the heat transfer rate reduces with an increase in Reynolds numbers, except for $\mathrm{b} / \mathrm{D}=0.05$ for the $\mathrm{V}$ Downstream. At $b / D=0.05$, the Nusselt number of the V-Upstream is greater than the V-Downstream for all Reynolds numbers. At $\mathrm{b} / \mathrm{D}=0.10$, the $\mathrm{Nu} / \mathrm{Nu}_{0}$ of the $\mathrm{V}$-Upstream is greater than the $\mathrm{V}$-Downstream when $\operatorname{Re}<17,000$, but slightly lower when $\operatorname{Re}>17,000$. At $b / D=0.15$, heat transfer in V-Upstream is greater than the V-Downstream when $\mathrm{Re}>$ 13,000 , but slightly lower when $\operatorname{Re} \geq 13,000$. At $b / D=0.20$, the $\mathrm{V}$ Upstream results in greater heat transfer compared with the VDownstream when $\operatorname{Re}>17,000$.

In the case of type $\mathrm{C} \mathrm{V}$-ring, the $\mathrm{Nu} / \mathrm{Nu}_{0}$ decreases with an increase in Reynolds numbers, except for $\mathrm{b} / \mathrm{D}=0.05$ for the $\mathrm{V}$-Downstream. At $\mathrm{b} / \mathrm{D}=0.05$ and 0.10 , the $\mathrm{V}$-Upstream results in greater heat transfer compared with the V-Downstream for all Reynolds numbers. At $\mathrm{b} / \mathrm{D}=$ 0.15 , the $\mathrm{Nu} / \mathrm{Nu} 0$ of $\mathrm{V}$-Upstream is greater than the $\mathrm{V}$-Downstream when $\operatorname{Re}>17,000$. At $b / D=0.20, \mathrm{Nu} / \mathrm{Nu}_{0}$ for both directions are found to be similar. 
The improvement in heat transfer rate of the tested section is due to the optimum helical pitch length of the vortex flow or swirling flow. Moreover, the vortex strength and the disturbance of the thermal boundary layer on the heat transfer surfaces are main factors for the enhanced heat transfer rate and thermal performance.

Figs. $13 \mathrm{a}, 13 \mathrm{~b}$ and $13 \mathrm{c}$ show the variation of $\mathrm{f} / \mathrm{f}_{0}$ with the Reynolds number at various ratios of $\mathrm{b} / \mathrm{D}$ and flow directions for type $\mathrm{A}, \mathrm{B}$ and $\mathrm{C}$, respectively. As shown in the figures, $\mathrm{f} / \mathrm{f}_{0}$ increases with an increase in Reynolds number and $\mathrm{b} / \mathrm{D}$ for all cases. The highest friction loss value is observed when $b / D=0.20$, but when $b / D=0.05$, the opposite trend is

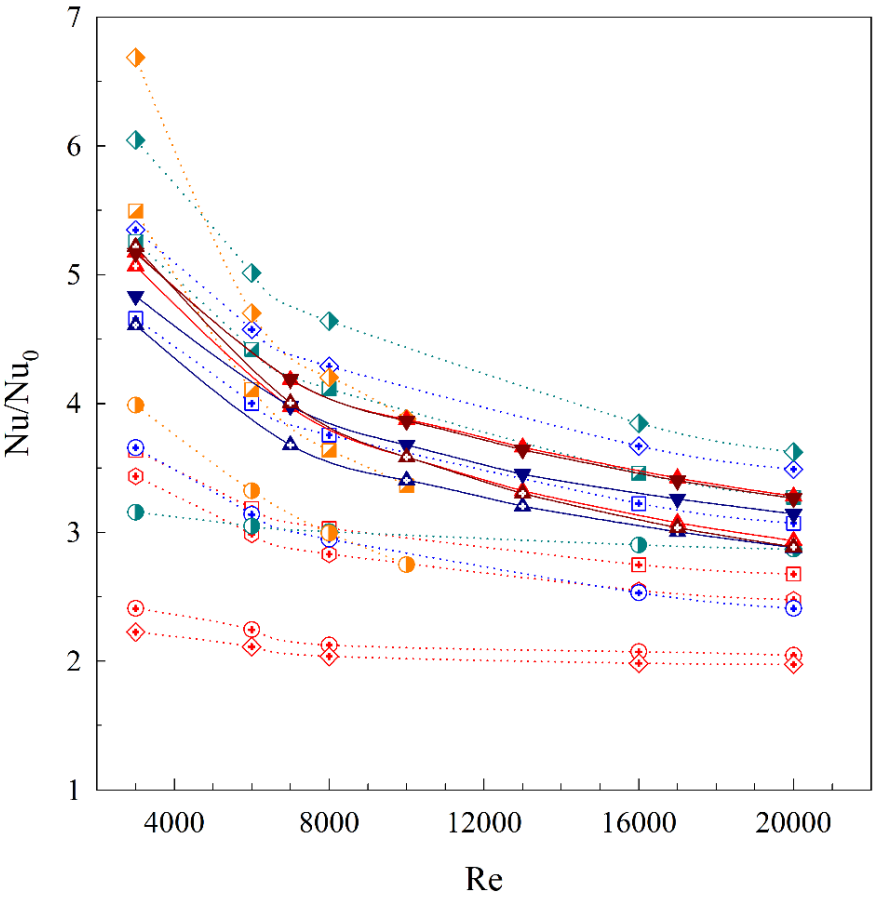

(a) observed for all V-ring types and flow arrangements. In the case of the V-Downstream, the attachment of the V-rings, compared with the plain pipe, produces $4.66-100.68,4.17-63.71$ and $3.28-68.38$ times higher friction loss for type A, B and C, respectively. As for the V-Upstream, the addition of the type $\mathrm{A}, \mathrm{B}$ and $\mathrm{C} \mathrm{V}$-rings, compared with the plain pipe, produces $5.00-96.55,4.73-74.21$ and $4.35-104.11$ times more friction loss, respectively. The V-rings with the V-Upstream, compared with the V-Downstream, increases more pressure loss, except for type A when $b / D=0.20$. The differences of friction factors for type $B$ and $C$, especially at high $\mathrm{b} / \mathrm{D}$ value, can be observed.

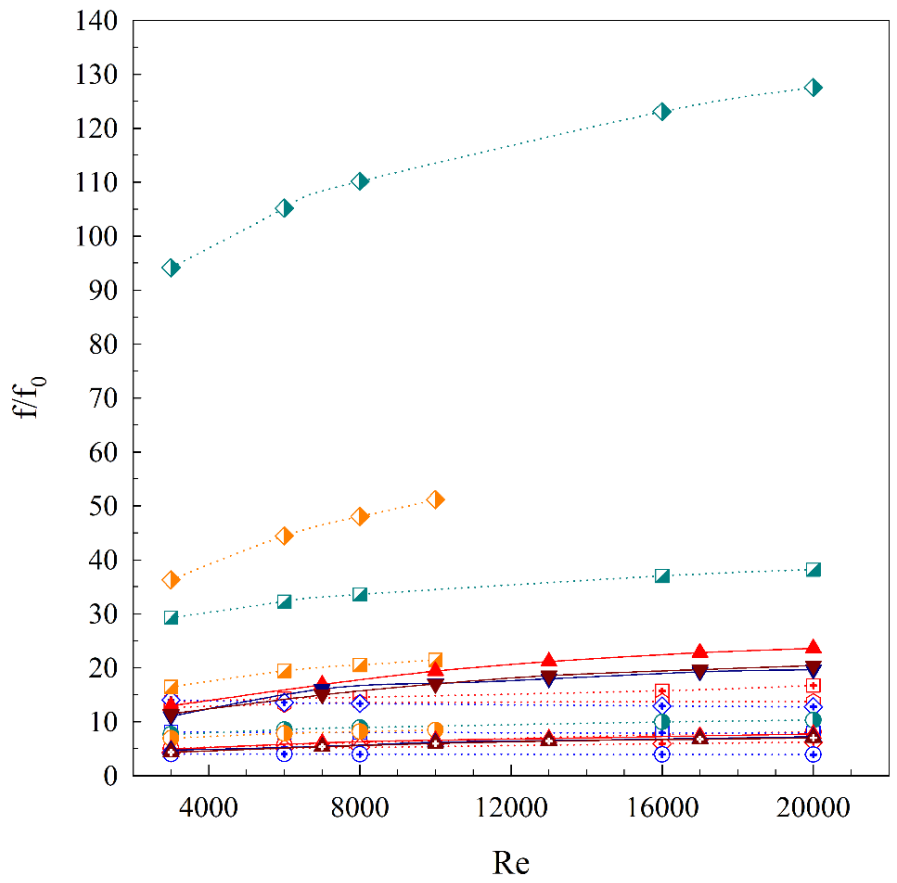

(b)

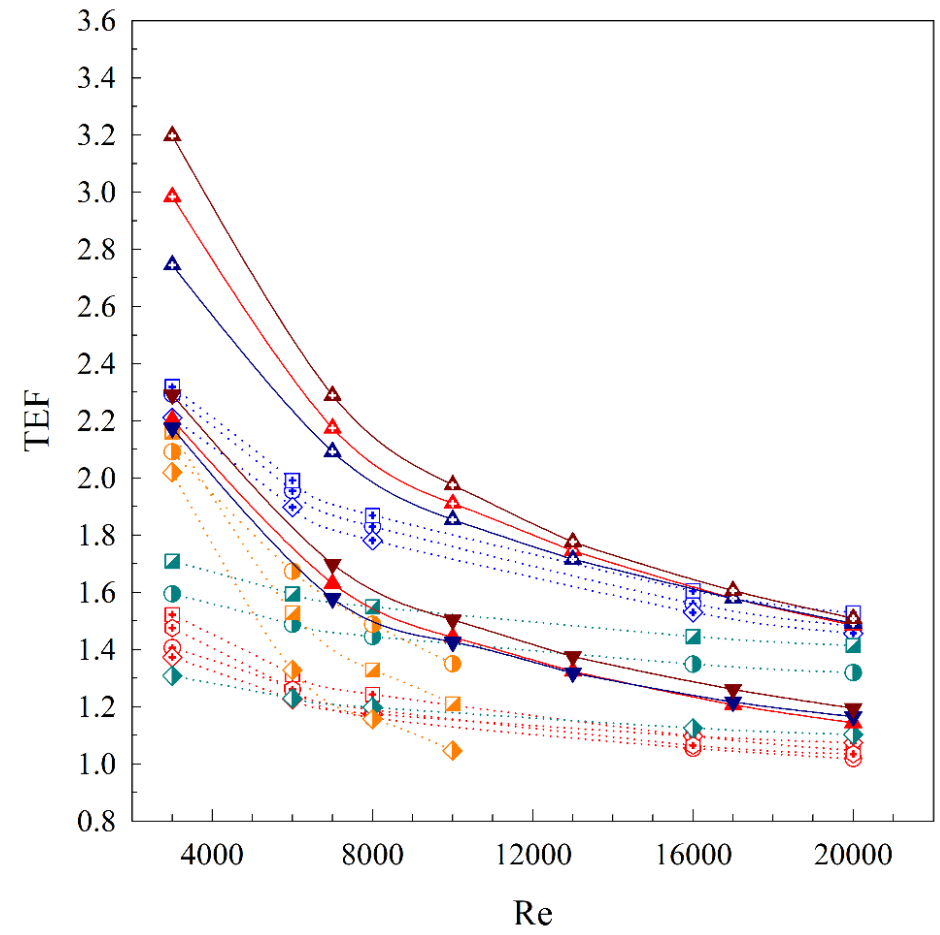

(c)

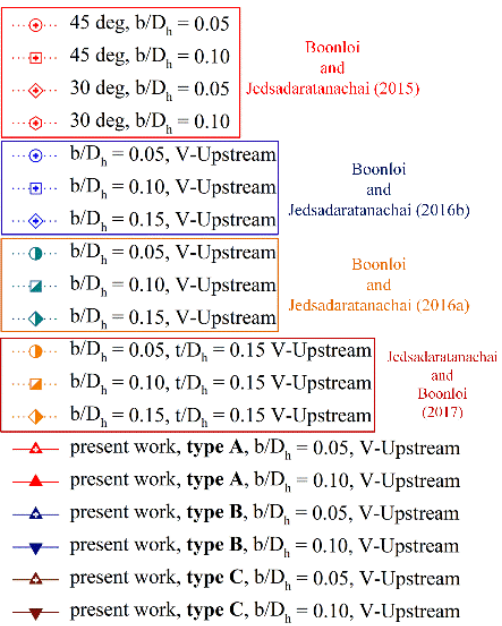

Fig. 15 Comparisons of (a) $\mathrm{Nu} / \mathrm{Nu}_{0}$, (b) f/fo and (c) TEF obtained from the present study with published works. 
The relationships between the TEF and the Reynolds number at different $\mathrm{b} / \mathrm{D}$ and Re values are plotted for type $\mathrm{A}, \mathrm{B}$ and $\mathrm{C}$ V-rings in Figs. $14 \mathrm{a}, 14 \mathrm{~b}$ and $14 \mathrm{c}$, respectively. As shown by the plots, the TEF decreases with increasing Reynolds numbers for all cases. In the case of the V-Downstream, the optimum TEF is observed when $b / D=0.10$. The TEF observed are 1.66, 1.68 and 1.95 for type A, B and C, respectively, at $\mathrm{Re}=3000$. In the case of the V-Upstream, the optimum TEF is observed when $\mathrm{b} / \mathrm{D}=0.05$. The TEF observed are 2.98, 2.74 and 3.10 for type $\mathrm{A}, \mathrm{B}$ and $\mathrm{C}$, respectively, at $\mathrm{Re}=3000$. The results suggest that in the case of V-Downstream and V-Upstream when $\mathrm{b} / \mathrm{D}=0.10$ and 0.05 , respectively, the optimum ratio between the Nusselt number and friction factor can be obtained at similar pumping power.

Figs. $15 \mathrm{a}, 15 \mathrm{~b}$, and $15 \mathrm{c}$ show the plots comparing $\mathrm{Nu} / \mathrm{Nu}_{0}, \mathrm{f} / \mathrm{f}_{0}$ and TEF obtained from the present results with those from the published works. As shown in the figures, the Nusselt number of the present work is not larger than other types of vortex generators, but the friction loss of the present work is very low, especially at $b / D=0.05$. Therefore, the $\mathrm{V}$ rings (types $\mathrm{A}, \mathrm{B}$ and $\mathrm{C}$ at $\mathrm{b} / \mathrm{D}=0.05$ of $\mathrm{V}$-Upstream) offers the highest TEF as compared with the published works.

\section{CONCLUSION}

The numerical analysis of flow topology and heat transfer in the round pipe heat exchanger attached with various configurations of the $\mathrm{V}$-rings is performed. The flow blockage ratios, V-ring types and flow directions are considered for the turbulent flow regime with the Reynolds number based on the inlet condition ranging between $3000-20,000$. The conclusion drawn from the numerical results is as follows.

The round pipe heat exchange with V-rings induces greater heat transfer compared with the pipe with no V-rings. The V-rings produce vortex flows which disturb the thermal boundary layer. The thermal boundary layer disturbance leads to the enhancement of heat transfer. The vortex flows also help to improve fluid blending in the pipe, another contributing factor to heat transfer improvement.

In view of heat exchanger design, to achieve the optimum TEF, the ratio of $b / D=0.10$ and 0.05 of the V-rings are recommended for the $\mathrm{V}$ Downstream and V-Upstream directions, respectively. In the present study, the best TEF is found to be approximately 3.10 for type $\mathrm{C}$ at $\mathrm{Re}=$ 3,000 and $\mathrm{b} / \mathrm{D}=0.05$. Compared with the pipe without V-rings, heat transfer is approximately $2.19-5.73$ times greater, depending on b/D, $\mathrm{Re}$, flow directions and V-ring types.

The V-rings also provide higher TEF than other types of vortex generators. Moreover, the structure of the V-rings makes them easy to install and maintain in round tube heat exchangers.

\section{ACKNOWLEDGEMENT}

"The authors would like to thank Assoc. Prof. Dr. Pongjet Promvonge for suggestions. This research was funded by King Mongkut's University of Technology North Bangkok, Contract no. KMUTNB-65-BASIC-18."

\section{SYMBOL}

b baffle height, $\mathrm{m}$

D round pipe diameter, $m$

f friction factor

h convective heat transfer coefficient, $\mathrm{W} \mathrm{m}^{-2} \mathrm{~K}^{-1}$

$\mathrm{k}$ thermal conductivity, $\mathrm{W} \mathrm{m}^{-1} \mathrm{~K}^{-1}$

$\mathrm{L} \quad$ periodic length of the physical model, $\mathrm{m}$

$\mathrm{Nu} \quad$ Nusselt number $(=\mathrm{hD} / \mathrm{k})$

$\mathrm{P} \quad$ pitch distance, $\mathrm{m}$

$\mathrm{p} \quad$ static pressure, $\mathrm{Pa}$

Re Reynolds number

$\mathrm{T}$ temperature, $\mathrm{K}$

$\bar{u} \quad$ mean velocity in channel, $\mathrm{m} \mathrm{s}^{-1}$

\section{Greek letter}

$\rho$ density, $\mathrm{kg} \mathrm{m}^{-3}$

$\mu \quad$ dynamic viscosity, $\mathrm{kg} \mathrm{m}^{-1} \mathrm{~s}^{-1}$

Subscript
$0 \quad$ plain duct

pp pumping power

Abbreviation

TEF Thermal Efficiency Factor $\left(=\left(\mathrm{Nu} / \mathrm{Nu}_{0}\right) /\left(\mathrm{f} / \mathrm{f}_{0}\right)^{1 / 3}\right)$

\section{REFERENCE}

Bahiraei, M., Mazaheri, N., and Moayedi, H., 2020, "Employing Vshaped Ribs and Nanofluid as Two Passive Methods to Improve Second Law Characteristics of Flow within a Square Channel: A Two-phase Approach", International Journal of Heat and Mass Transfer, 151, Article 119419.

https://doi.org/10.1016/j.ijheatmasstransfer.2020.119419

Bahiraei, M., Mazaheri, N., Hosseini, Y., and Moayedi, H., 2019, “A Two-phase Simulation for Analyzing Thermohydraulic Performance of $\mathrm{Cu}-$ water Nanofluid within a Square Channel Enhanced with $90^{\circ} \mathrm{V}$ Shaped Ribs", International Journal of Heat and Mass Transfer, 145, Article 118612.

https://doi.org/10.1016/j.ijheatmasstransfer.2019.118612

Bahiraei, M., Monavari, A., and Moayedi, H., 2020, "Second Law Assessment of Nanofluid Flow in a Channel Fitted with Conical Ribs for Utilization in Solar Thermal Applications: Effect of nanoparticle shape", International Journal of Heat and Mass Transfer, 151, 2020, Article 119387.

https://doi.org/10.1016/j.ijheatmasstransfer.2020.119387

Bai, W., Chen, W., Yang, L., and Chyu, M.K., 2019, "Numerical Investigation on Heat Transfer and Pressure Drop of Pin-fin Array Under the Influence of Rib Turbulators Induced Vortices", International Journal of Heat and Mass Transfer, 129, 735-745.

https://doi.org/10.1016/j.ijheatmasstransfer.2018.10.022

Bai, W., Liang, D., Chen, W., and Chyu, M.K., 2019, "Investigation of Ribs Disturbed Entrance Effect of Heat Transfer and Pressure Drop in Pin-fin Array", Applied Thermal Engineering, 162, Article 114214. https://doi.org/10.1016/j.applthermaleng.2019.114214

Boonloi, A., and Jedsadaratanachai, W., 2014, "Thermal Performance Analysis and Empirical Correlations for Laminar Forced Convection over $30^{\circ}$ V-baffled Square Channel", Advances in Mechanical Engineering, 2014, Article 930272.

https://doi.org/10.1155/2014/930272

Boonloi, A., and Jedsadaratanachai, W., 2015, "Turbulent Forced Convection in a Heat Exchanger Square Channel with Wavy-ribs Vortex Generator", Chinese Journal of Chemical Engineering, 23-8, 1256-1265. https://doi.org/10.1016/i.cjche.2015.04.001

Boonloi, A., and Jedsadaratanachai, W., 2016a, "Numerical Investigation on Turbulent Forced Convection and Heat Transfer Characteristic in a Square Channel with Discrete Combined V-baffle and V-orifice", Case Studies in Thermal Engineering, 8, 226-235.

https://doi.org/10.1016/j.csite.2016.07.003

Boonloi, A., and Jedsadaratanachai, W., 2016b, "Numerical Investigation on Turbulent Forced Convection in Heating Channel Inserted with Discrete V-Shaped Baffles", Journal of Mathematics and Statistics, 12-1, 43-58.

https://doi.org/10.3844/jmssp.2016.43.58

Boonloi, A., and Jedsadaratanachai, W., 2018a, "Effect of Flow Attack Angle for V-Wavy Plate on Flow and Heat Transfer in a Square Channel Heat Exchanger", Journal of Engineering, 2018, Article 9487070. https://doi.org/10.1155/2018/9487070 
Boonloi, A., and Jedsadaratanachai, W., 2018b, "Effect of Location in Transverse Plane for 45-degree V-baffle on Flow and Heat Transfer Mechanisms in a Square Channel", Frontiers in Heat and Mass Transfer, 11-29.

https://doi.org/10.5098/hmt.11.29

Boonloi, A., and Jedsadaratanachai, W., 2019a, "Numerical Study on Flow and Heat Transfer Mechanisms in the Heat Exchanger Channel with V-orifice at Various Blockage Ratios, Gap Spacing Ratios, and Flow Directions", Modelling and Simulation in Engineering, 2019, Article 8656435.

https://doi.org/10.1155/2019/8656435

Boonloi, A., and Jedsadaratanachai, W., 2019b, "Thermal Performance Improvement in a Square Channel Heat Exchanger with Various Parameters of V-wavy Plates", Frontiers in Heat and Mass Transfer, 121.

https://doi.org/10.5098/hmt.12.1

Cengel, Y.A., and Ghajar, A.J., 2015, "Heat and Mass Transfer: Fundamentals \& Applications, Fifth Edition in SI Units", McGraw-Hill Education, ISBN 978-981-4595-27-8.

Eiamsa-ard, S., Ruengpayungsak, K., Thianpong, C., Pimsarn, M., and Chuwattanakul, V., 2019, "Parametric Study on Thermal Enhancement and Flow Characteristics in a Heat Exchanger Tube Installed with Protruded Baffle Bundles", International Journal of Thermal Sciences, 145, Article 106016.

https://doi.org/10.1016/j.ijthermalsci.2019.106016.

Jedsadaratanachai, W., and Boonloi, A., 2014, "Effects of Blockage Ratio and Pitch Ratio on Thermal Performance in a Square Channel with $30^{\circ}$ Double V-baffles", Case Studies in Thermal Engineering, 4, 118128.

https://doi.org/10.1016/j.csite.2014.08.002

Jedsadaratanachai, W., and Boonloi, A., 2017, "Performance Analysis and Flow Visualization in a Round Tube Heat Exchanger Inserted with Wavy V-ribs", Advances in Mechanical Engineering, 9-9, 1-16.

https://doi.org/10.1177/1687814017724091

Jedsadaratanachai, W., Jayranaiwachira, N., and Promvonge, P., 2015, "3D Numerical Study on Flow Structure and Heat Transfer in a Circular
Tube with V-baffles", Chinese Journal of Chemical Engineering, 23-2, 342-349.

https://doi.org/10.1016/i.cjche.2014.11.006

Jiang, G., Gao, J., Shi, X., Li, F., and Xu, L., 2020, "Flow and Heat Transfer Characteristics of the Mist/steam Two-phase Flow Cooling the Rectangular Channel with Column-row-ribs", International Journal of Heat and Mass Transfer, 156, Article 119737.

https://doi.org/10.1016/j.ijheatmasstransfer.2020.119737

Kongkaitpaiboon, V., Nanan, K., and Eiamsa-ard, S., 2010, "Experimental Investigation of Convective Heat Transfer and Pressure Loss in a Round Tube Fitted with Circular-ring Turbulators", International Communications in Heat and Mass Transfer, 37, 568-574. https://doi.org/10.1016/j.icheatmasstransfer.2009.12.016

Li, F., Ma, Q., Xin, G., Zhang, J., and Wang, X., 2020, "Heat Transfer and Flow Characteristics of Microchannels with Solid and Porous Ribs", Applied Thermal Engineering, 178, Article 115639.

https://doi.org/10.1016/j.applthermaleng.2020.115639

Li, Y., Rao, Y., Wang, D., Zhang, P., and Wu, X., 2019, "Heat Transfer and Pressure Loss of Turbulent Flow in Channels with Miniature Structured Ribs on One Wall", International Journal of Heat and Mass Transfer, 131, 584-593.

https://doi.org/10.1016/j.ijheatmasstransfer.2018.11.067

Matsubara, K., Ohta, H., and Ishino, T., 2020, "Direct Simulation of Inlet Region Heat Transfer in a Channel with Repeated Ribs Under Isothermal Wall Heating Condition", International Journal of Thermal Sciences, 154, Article 106408.

http://doi.org/10.1016/j.ijthermalsci.2020.106408

Phila, A., Eiamsa-ard, S. and Thianpong, C., 2020, "Thermal Performance Evaluation of a Channel Installed with Inclined-Baffle Turbulators", Arabian Journal for Science and Engineering, 45, 609621.

https://doi.org/10.1007/s13369-019-04097-x

Piriyarungrod, N., Kumar, M., Thianpong, C., Pimsarn, M., Chuwattanakul, V., and Eiamsa-ard, S., 2018, "Intensification of Thermo-hydraulic Performance in Heat Exchanger Tube Inserted with Multiple Twisted-tapes", Applied Thermal Engineering, 136, 516-530. https://doi.org/10.1016/j.applthermaleng.2018.02.097. 